https://doi.org/10.19195/0137-1150.174.5

Data przesłania artykułu: 18.03 .2020

Data akceptacji artykułu: 25.03.2020

\title{
EWA SZPERLIK
}

Uniwersytet im. Adama Mickiewicza w Poznaniu, Polska (Adam Mickiewicz University, Poland)

\section{Pamięć i tożsamość w powieściach Ludwiga Bauera (Karusel i Toranj kiselih jabuka)}

\section{Memory and identity in Ludwig Bauer's novels (Karusel and Toranj kiselih jabuka)}

\section{Abstract}

In the works of Ludwig Bauer, a significant place is given to the autobiographical memory of the past, strongly connected with the discourse of identity, lost childhood, collective amnesia; it is related to body memory, place memory, and in the characters' biographies there is usually present (overt or covert) Plato's eikon (seen as a trace imprinted on the psyche and the mind), whose finding and explaining stimulates the plot and the story. Community memory is stored (A. Assmann) in the individual memory of its members. The aim of the proposed topic is to explore - with the use of interdisciplinary, methodological achievements in the field of memory discourse - the hermeneutics of L. Bauer's selected works. As a result, the disquisition provides an analysis of literature in the process of forming memory and identity in the area of the former Yugoslavia, as well as literature as a medium of memory and "distinctive symbol system" (B. Neumann) in the whole culture of memory.

Keywords: collective memory, individual memory, identity, literature as a memory medium, Yugoslav post-memory

\section{Pamćenje i identitet u romanima Ludwiga Bauera (Karusel i Toranj kiselih jabuka)}

\section{Sažetak}

U romanesknom stvaralaštvu L. Bauera iznimno važno mjesto zauzima pamćenje i prošlost, silno povezane s pitanjima identiteta pojedinca (izgubljenog u djetinjstvu), kolektivnog zaborava, 
tjelesnog pamćenja, sjećanja na vrijeme i prostor. U životopisima Bauerovih književnih junaka često je prisutan (vidljiv ili sakriven) platonski eikon (kao trag otisnut u prošlosti) kojeg polagano razotkrivanje tijekom priče determinira spoznaju o pamćenju ne samo pojedinca nego i njegove okoline (kolektivno pamćenje podunavskih Švaba). Uz pomoć odabranih interdisciplinarnih metoda analize književnog djela preuzetog iz područja memory boom (A. Assmann, B. Neumann i dr.) u proznom stvaralaštvu tog istaknutog hrvatskog pisca nalazimo ne samo dugo prešućivanu temu sudbine jugoslavenskih folksdojčera nakon II svjetskog rata, nego i ulogu autobiografskog žanra u procesu oblikovanja zajedničkog pamćenja i identiteta na prostoru kulture u bivšoj Jugoslaviji.

Ključne riječi: kolektivno pamćenje, pamćenje pojedinca, identitet, knjižvnost kao nosilac pamćenja, postpamćenje u Jugoslaviji

W powojennej Jugosławii egzystencja mniejszości niemieckiej zależała od tożsamościowej mimikry, wyparcia, zapomnienia, odrzucenia, zwłaszcza wśród członków następnych pokoleń, gotowych do daleko idącej integracji przez całkowite wtopienie się w zastępczą społeczność i kulturę gospodarza. W wyniku najnowszej rewizji wydarzeń historycznych jugosłowiańscy folksdojcze ${ }^{1}$ stali się ofiarami etnocydu. Echem tej sytuacji są często obecne w powieściach Ludwiga Bauera głosy krytycznej pamięci o Jugosławii, przedstawionej z perspektywy „niemieckiego odszczepieńca”, rozprawiające się z wieloma dominującymi w państwie Tity mitami:

zapravo sam osjećao da baka načelno ne trpi nikakve institucije te nove države kojom su upravljali divljaci koji su došli iz šume, uglavnom s namjerom da poštenom svijetu otimaju kuće i da po tavanima traže skrivenu svinjsku mast, koja je, usput rečeno, bila u podrumu, u kanti zakopanoj u zemlju, ispod drvene ploče na kojoj je bio sloj zemlje i hrpa krumpira. (Bauer, 2013, s. 68-69)

Dla Paula Ricoeura ,wszystko, co tworzy kruchość tożsamości, stanowi zarazem powód do manipulowania pamięcią, głównie za pośrednictwem ideologii” (Ricoeur, 2006, s. 590). Bohaterowie powieści Bauera to ofiary polityki pamięci

1 Należy zwrócić uwagę, że w języku chorwackim określenie „folksdojcz” (folksdojčer, czasami pisane wielką literą — Folksdojčer) w mniejszym stopniu niż w polszczyźnie zawiera negatywną konotację, na przykład podpisujący volkslistę, kolaborujący z niemieckim okupantem. W chorwackim Słowniku wyrazów obcych znajdujemy wyjaśnienie, że folksdojčer to ktoś przynależący do mniejszości niemieckiej w Królestwie Jugosławii do roku 1941 i w czasie II wojny światowej, zrzeszony w rozmaitych niemieckich organizacjach lub stowarzyszeniach (zob. Anić, Goldstein, 2004, s. 446). Chorwacki historyk Vladimir Geiger, zajmujący się od lat problematyką losów mniejszości niemieckiej na terenie Jugosławii, we wstępie do jednej ze swoich publikacji wyjaśnia, że słowiańska ludność określała swoich sąsiadów — niemieckich kolonistów — mianem Szwab(y) (Švabo, Švaba), o pejoratywnym wydźwięku; w dyskursie naukowym funkcjonuje natomiast określenie Niemcy naddunajscy (chorw. Podunavski Švabe, niem. Donauschwaben), które ugruntowało się po I wojnie światowej jako nazwa kolektywna Niemców zamieszkujących tereny Węgier, Banatu, Bački, Baranii, Srijemu i Slavonii. Ponadto terminem Volksdeutcher Niemcy mieszkający w Rzeszy nazywali wszystkich pozostałych Niemców, urodzonych i zamieszkujących inne tereny poza granicami Niemiec (zob. Geiger, 1997, s. 9-10). 
i polityki tożsamości, często wymazywanej lub narzucanej przez dyskurs władzy. Zdaniem niemieckiej badaczki Astrid Erll literatura to dysponujący władzą nośnik pamięci zbiorowej — zarówno jako medialna rama pamięci indywidualnej, jak i medium magazynujące i cyrkulacyjne pamięci zbiorowo-kulturowej (Erll, 2009, s. 247). Jak z kolei zauważa Birgit Neumann:

Podejmowanie kwestii skomplikowanych zależności, zachodzących między dziełami literackimi a polami tematycznymi, obejmującymi pamięć i tożsamość, umożliwia wgląd w społeczne procesy nadawania sensów, w dominujące treści pamięci, hierarchie wartości, jak również rolę, jaką odgrywać może literatura w przyswajaniu doświadczeń. (Neumann, 2009, s. 249)

W twórczości Ludwiga Bauera znamienne miejsce zajmuje, nacechowana autobiograficznie, pamięć przeszłości, wyraźnie połączona z dyskursem tożsamościowym oraz kwestiami utraconego dzieciństwa i zbiorowej amnezji. Wiąże się ona także z pamięcią ciała, pamięcią miejsca, a w życiorysach powieściowych bohaterów zazwyczaj jest obecny (widoczny lub ukryty) platoński eikon (rozumiany jako odciśnięty ślad w psychice, umyśle), do którego dotarcie i którego rozwikłanie staje się stymulatorem fabuły i opowieści. Pamięć wspólnoty jest zmagazynowana (A. Assmann) w pamięciach indywidualnych jej przedstawicieli.

W kontekście najnowszej literatury chorwackiej po rozpadzie federacji południowosłowiańskiej dzieła nacechowane autobiograficznie lub eksponujące historie jednostkowe mają spory wkład w procesie przywracania pamięci zbiorowej przemilczanych w państwie Tity niechlubnych kart historii jugosłowiańskiej, do których zalicza się między innymi tragiczny los naddunajskich Szwabów². Do eksploracji tego problemu niezwykle przydatne okazują się interdyscyplinarne narzędzia z obszaru memory boom, jak na przykład pamięć przeszłości (A. Szpociński), głos słabych bohaterów historii (M. Velčić), pamięć jako przeciw-historia (P. Connerton), usypianie pamięci (M. Golka), wymazywanie, zacieranie śladów (P. Ricoeur) czy wypalone żużle pamięci (C. Levi-Strauss). Istotnymi elementami są również pamięć autobiograficzna, pojęcie autofikcji (A. Zlatar), a także zjawiska dotyczące zawiłości tożsamościowych (postmodernistycznie ujmowana tożsamość hybrydyczna: Z. Baumann, P. Ricoeur, Ž. Paić, G. Dziamski, czy tożsamość wielokrotna: L. Niethammer), które na obszarze wieloetnicznych Bałkanów są ważnym aspektem kulturowym.

W analizowanych powieściach chorwackiego pisarza szczególnego znaczenia w opisywaniu rzeczywistości nabiera oddolna perspektywa i osobista pamięć bohaterów (fokalizacja/akt narracyjny: Mieke Bal). Pamiętanie jest przede wszystkim łącznikiem między czasem a przestrzenią, określonym przez badaczkę jako mapowanie (mapping). Zwłaszcza w opowieściach $\mathrm{z}$ akcją toczącą się na obszarze, z którego ludzie byli wypierani, a następnie z retrospektywnym powrotem do czasu, kiedy dane miejsce stało się inną przestrzenią (Bal, 2012, s. 152). Wśród nośników pamięci, do których należą fotografie, pomniki, miejsca pamięci,

\footnotetext{
2 Szerzej o tym zob. Geiger, 1997.
} 
wszelkie rytuały upamiętniające itp., szczególne znaczenie mają teksty literackie, zwłaszcza autobiografie, testymonia, mikrohistorie (E. Domańska). Z pamięci będącej pomostem między teraźniejszością a czasem przeszłym wyodrębniono postpamięć (M. Hirsch) — rodzaj pamięci dziedziczonej, narracji (często traumatycznej) przekazywanej z pokolenia na pokolenie (Hirsch, 2011, s. 28-36).

Znany, ceniony i chętnie czytany Ludwig Bauer, urodzony w Sisaku w 1941 roku, chorwacki pisarz wywodzący się z mniejszości naddunajskich Szwabów, jest zadeklarowanym krypto-Niemcem, którego twórczość została zdominowana przez niemal obsesyjny temat tłumionej tożsamości niemieckiej w Jugosławii po II wojnie światowej. Akcja wielu jego powieści rozgrywa się w panońskim (fikcyjnym) miasteczku Gradec, którego bohaterowie borykają się z brzemieniem złożonej tożsamości. Typowy dla Bauera temat o przemilczanych przez powojenną historię tragicznych losach jugosłowiańskich folksdojczów został wpleciony w krytyczną opowieść o walce zwykłego człowieka z systemem politycznym (socjalistyczna Jugosławia) opresjonującym jednostkę ${ }^{3}$. U wielu powieściowych postaci ewolucja poczucia tożsamości uzależniona jest od stopniowego odpamiętywania związanej z nią przeszłości. W konstrukcji świata przedstawionego znajdujemy mocno wyeksponowany aspekt psychologiczny pamięci (wypieranie, zapominanie, odpominanie itp.) związany z rekonstrukcją samoidentyfikacji wielu głównych bohaterów, których można uznać za alter ego samego autora. Zawierająca wiele wątków autobiograficznych powieść Toranj kiselih jabuka (Wieża kwaśnych jabłek) z 2013 roku została odczytana w kluczu intertekstualnej autobiografii, choć na samym początku utworu pisarz odżegnuje się od takiego sposobu interpretacji.

Dzieła chorwackiego prozaika dają się określić mianem autofikcjonalnych. Podążając za koncepcją Philippe’a Lejeuna, można zauważyć, że świat przedstawiony w dziełach chorwackiego autora wpisuje się w kategorię przestrzeni autobiograficznej, a także takiego nastawienia lekturowego, w którym teksty fikcjonalne czytane są jak teksty autobiograficzne. Tym samym działanie paktu autobiograficznego zostaje rozciągnięte na istotną część twórczości danego pisarza. Ów specyficzny, wtórnie niejako ustanawiany pakt Lejeune nazywa paktem fantazmatycznym (Lejeune, 2010, s. 14-15). Autobiografia, dziennik, pamiętnik pozwala — zdaniem badacza — „przetrwać” i „zachować coś w pamięci”4.

Skomplikowane, a także tragiczne położenie przedstawicieli niemieckiej mniejszości oraz ich potomków żyjących w titowskiej Jugosławii było pokłosiem sytuacji politycznej po II wojnie światowej. Ludwig Bauer w jednym z wywiadów stwierdził: „Drugi svjetski rat na mene je utjecao puno više nego što sam dugo bio svjestan. Kao dijete nemate objektivan ili kritički odnos prema onome što proživlja-

3 Problem ten został wyeksponowany między innymi w powieściach: Kratka kronika porodice Weber (1990), Patnje Antonije Brabec (2008) i Zavičaj, zaborav (2010).

4 ,Autor pisze przede wszystkim dla samego siebie, jest swoim własnym odbiorcą w przyszłości, to nowoczesna wersja mnemoniki, sztuki zapamiętywania, zorganizować zapis przeszłości w »tożsamość narracyjną《" (Lejeune, 2010, s. 39). 
vate, ali kasnije se to vrati, i čovjek je u stanju o tome izgraditi određenu literarnu istinu" (Stjepandić, 2014). Z kolei na jedno z pytań, dotyczące poczucia narodowej przynależności, odpowiedział, w wolnym tłumaczeniu: ,jestem Niemcem, tak jest napisane w spisie wyborców. To jest moje pochodzenie i przywiązanie do niemieckiej kultury, ale jestem również Chorwatem za sprawą języka i kultury. Zatem Niemcem, który pisze po chorwacku. Próbuję łączyć te dwie przynależności kulturowe. Nie stoją one z sobą w sprzeczności” (Stjepandić, 2014).

Spośród wielu czynników wpływających na kształtowanie się tożsamości, takich jak miejsce i czas urodzenia, pochodzenie etniczne, środowisko, wykształcenie, język, czasem wygląd zewnętrzny (kolor skóry), w świecie przedstawionym powieści Bauera jednym z czynników okazuje się pamięć. Osią problemu powieściowych zdarzeń i pamięci o przeszłości jest przypisany reprezentantom naddunajskich Szwabów stygmat niemieckiej winy za zbrodnie popełnione przez nazistów. Pamięć o mitycznym ojcu determinuje tożsamość głównego protagonisty utworu Toranj kiselih jabuka. Tożsamość i pamięć całej rodziny chłopca, którego ojciec przeszedł na stronę partyzantów i zginął w czasie wojny jako bohater, jest rozpostarta między niemieckością, chorwackością i jugosłowiańskością. Z jednej strony chłopiec styka się z głęboko zakorzenionym poczuciem chorwackości i słowiańskości, za sprawą pochodzącego z nacjonalistycznie nastawionej Liki dziadka ze strony matki (Dida Marko), podczas gdy po drugiej stronie sytuuje się w jego rodzinie mocne poczucie niemieckości, będące dziedzictwem przodków po mieczu:

Djeda Ludwiga Bauera za razliku od Dida Marka zvao sam samo Dida. [...] djed se bio školovao u Austriji. Didin otac, moj pradjed, bio je podunavski Nijemac iz Mađarske. [...] Na čudan način i Dida je tu tradiciju smatrao dijelom svoga njemačkog identiteta. „Kad god u Hrvatskoj postane teško, mi Švabe moramo podmetnuti leđa”, rekao mi je jednom. [...] „Kako to - mi Švabe?” pitao sam. [...] „Nemaš se zašto brinuti”, umirivao me je. „Pravi su Švabe oni koji su pravi Jugoslaveni. Njima svaka čast!”. (Bauer, 2013, s. 60-65)

Na wyraźnie wyeksponowaną w utworze pamięć dziecka nakładają się wspomnienia dorosłego już bohatera, dotyczące emocjonalnego podejścia do konieczności ciągłego przystosowywania się i — zgodnie z panującymi regułami - wyzbywania się cząstek własnej tożsamości. Wskazuje na to choćby fakt przeprowadzki głównego bohatera z Sisaka do Makarskiej, gdzie zamieszkał wraz z matką i ojczymem. Ze względu na swoje niemieckie pochodzenie chłopiec przez całe życie musi się dostosowywać do otoczenia i okoliczności, a jednocześnie zawsze pozostaje Innym. Na szczególną uwagę zasługuje jego konfrontacja z mieszkańcami Dalmacji, a także rola języka w procesie kształtowania własnej samoidentyfikacji, jego przypominania bądź przymusowego wypierania z pamięci:

Kada sam, kratko nakon dolaska u Makarsku krenuo u školu, bio sam svima neobičan. I oni su meni bili novi, ali pokušao sam se snaći među novim licima, s novim navikama, s novim pravilima ponašanja; nastojao sam biti prilagodljiv. Većina đaka imala je prema meni znatno naglašeniji, emfatičniji odnos. Moje ime bilo im je čudno, bilo im je čudno da netko dolazi iz kraja koji nije tu pod Biokovom, a iznad svega bio im je čudan moj govor. [...] Doi- 
sta, nikada nisam u potpunosti prihvatio sisački govor; nisam ga sasvim naučio. Jezik kojim se očekivalo da govorim stalno se mijenjao. Prvo je jako važno bilo govoriti njemački, nisam to osjećao kao pritisak, bilo mi je sasvim prirodno da u upotrebi postoje dva različita jezika, i čak me nije zbunjivalo to što sam s jednima govorio jednim, a s nekim drugima drugim jezikom. Zbunilo me je to što njemački odjednom nisam smio govoriti, kazna za svaku njemačku riječ bila je, ili mogla biti, pljuska, šamar prepun strasti, emocija koje se uopće nisu ticale mene. „Švabe su krivi što je tvoj tata mrtav”, govorila je majka. „Kad čujem njemački, zaboli me duša". Potisnuo sam svoj njemački u neku sasvim mračnu dubinu svoje unutrašnjosti, ostala mi je inhibicija za ostatak života [...]. Ostalo mi je također nejasno i neraščišćeno pitanje koliko je jezik povezan s identitetom, s pripadnošću. (Bauer, 2013, s. 112)

Podświadome poczucie odmienności u protagonisty dochodzi do głosu podczas krótkiej podróży do Niemiec Zachodnich: „Na način, koji nisam sasvim dobro razumio, u zemlji svojih predaka osjećao sam se kod kuće od prvoga posjeta" (Bauer, 2013, s. 419).

Istotnym elementem przeżywania przeszłości są zmysły (Szperlik, 2015, s. 377$)^{5}$. W tekstach literackich Bauera pamięć dziecka przeplata się ze wspomnieniami dojrzałego podmiotu mówiącego w iście proustowskim stylu, czego jest świadomy sam autor/narrator, który francuskiego pisarza nazywa swoją bratnią duszą: „Proust je bio moj srodnik” (Bauer, 2013, s. 419). Pamięć zmysłów uwidocznia się szczególnie w poetyckim opisie zapachu morza i rzeki:

More je mirisalo. I rijeka je mirisala, ali drugačije. U tim dvama mirisima bila je zajednička nota, valjda dašak sublimirana joda. Ali značajno je bilo to da se i zatvorenih očiju osjeti blizina beskonačne vodene površine, koja ne prestaje unutar čovjekova dohvata, a sama seže daleko koliko i misao. Možda se u tom mirisu krila i tajna primordijalne veze s medijem iz kojeg smo došli, u kojem je ponikao život. Možda je zaista negdje u našim genetskim kodovima upisan i onaj koji nas podsjeća da je vodeni dom iskonskiji od kopnenoga. Među iskonske poticaje spada valjda i sklonost ribolovu. (Bauer, 2013, s. 122)

Jednym z zapachów stymulujących wspomnienia z dzieciństwa jest specyficzna woń obory, w której główny bohater często przesiadywał jako mały chłopiec:

Svinjara sam doživljavao pravim i punim čovjekom. Nije me smetao miris životinjske nastambe koji je nosio na sebi, pamtio sam taj miris iz bakine staje, kamo sam se sklanjao u toplinu kada je dvorištem šibao zimski vjetar i nalazio mir u pogledu na kravlje oko; imao sam tada dojam da me Rumava gleda kao svoje vlastito tele, a tu i tamo doista bi mi i liznula ruku ili čelo. Nije me smetao ni miris sijena na kojem je vjerojatno spavao, ni uglačani sloj masnoće na njegovim dekama. Sve je to bio miris nekakve idealne Prirode, miris idealnog, skladnog života. Sjetio sam se, pomalo neodređeno, i nekog Tolstojeva seljaka koji je odlazio u šumu s komadom suhog kruha i ostajao u šumskom bespuću danima. (Bauer, 2013, s. 158-159)

W ujęciu psychologicznym możliwości percepcyjne wzroku, słuchu, dotyku i smaku sprawiają, że narządy zmysłów wzbogacają i chronią pamięć. Lutz Niethammer podkreśla spontaniczne działanie i asocjacyjny charakter pamięci, dzięki

5 W kontekście literatury obszaru postjugosłowiańskiego szerzej na ten temat pisałam w artykule Przeszłość odkrywana zmysłami. Reminiscencje zapachów i smaków w autobiograficznej prozie obszaru postjugosłowiańskiego (Szperlik, 2015). 
czemu pojęcia, nazwiska, daty, obrazy przywołane przez samego relacjonującego mogą zostać połączone z nowymi historiami. „Przedpojęciowo istotne przeżycie jest, jak się wydaje, przechowywane w pamięci w postaci obrazu scenicznego, który można przedstawić w sposób anegdotyczny" (Niethammer, 2014, s. 40). Przez pryzmat doznań węchowo-smakowych bohater przywołuje także wspomnienie pierwszego aktu cielesnego z przypadkowo poznaną dziewczyną, odnosząc je do sytuacji o charakterze ogólnym:

Taj prvi trenutak prodiranja u žensku toplinu ostaje vjerojatno muškarcima svetom uspomenom za cijeli život. Moja je uspomena bila narušena mirisom konjaka, grčem koji ju je zgrabio u desnoj nozi baš u odlučnom trenutku i nenadanim napadom mučnine: dok sam još sav izbezumljen i znojan ležao na leđima na poplunu koji nismo uspjeli skloniti, ona je povraćala u kupaonici. (Bauer, 2013, s. 224)

Przejawem autoreferencji w procesie narracji wiedzionej przez Bauera jest pamięć pisarza - z racji wykonywanego przez bohatera zawodu często podróżującego literata i tłumacza wspomnienia mężczyzny przesycone są licznymi przywołaniami (poza wymienionym już M. Proustem): Lwa Tołstoja, Honoré de Balzaca, Thomasa Manna czy Milana Kundery. Akt pisania, tworzenia, przypominania oraz literatura tworzą assmanowski magazyn pamięci: „Kada sam se vratio u bolnicu, počeo sam razmišljati o tome kako ću se jednoga dana ipak morati vratiti u onaj vanjski svijet. [...] Osjetio sam da želim premostiti granicu između ta dva svijeta, i nekako se pisanje nametnulo, ili izronilo u mojoj svijesti kao najbolji put" (Bauer, 2013, s. 233).

W powieści Karusel ili Gabrijela naviješta novo doba (Karuzela, albo Gabriela obwieszcza nowe czasy) z 2011 roku inny reprezentant tożsamości hybrydycznej, Żyd Miroslav (właśc. Šalom Swarz), wychowany przez naddunajskich Niemców (rodzina Baumannów) jako Frederik, wyjeżdża do Ameryki, by po kilku dekadach przybyć do dawnej ojczyzny z powodu śmierci matki. Powrót ten okazuje się wspomnianym wcześniej mapowaniem przestrzeni. Obszar fikcyjnego miasteczka Gradec nie jest już tym samym miejscem, które Miroslav niegdyś opuścił. Nosi ono znamiona niedawnej bolesnej przeszłości, nie tylko wydarzeń spowodowanych II wojną światową, ale ukazuje też niekorzystne losy wielu etnosów w Jugosławii po roku 1945 (wypędzenia Niemców naddunajskich, również konsekwencje wcześniejszych bratobójczych walk między ustaszami, czetnikami, partyzantami, komunistami).

Skomplikowana, trójwymiarowa tożsamość emigranta Šaloma/Fredericka/ Miroslava została poddana rekonstrukcji pamięci. Przybywszy po 45 latach do Jugosławii, do swego zavičaju (chorw. mała, lokalna ojczyzna, strony rodzinne, kraj lat dzieciństwa, wspomnień, rodzinnych korzeni), mężczyzna odnawia relacje z dawną miłością Gabrielą. Mimo że bohater nosi imię oznaczające „człowieka pokoju" w trzech odrębnych językach i kulturach (żydowskiej, niemieckiej i chorwackiej), paradoksalnie przeciwności losu ukształtowały w nim dość neurotyczną, 
hermetyczną i nieufną osobowość ${ }^{6}$. O złożoności swojej identyfikacji protagonista mówi ze znaczną dozą ironii, lecz także rozgoryczenia:

Kakav je to bio trenutak sadašnjosti koji se pretvorio u tako značajan trenutak prošlosti? Kako sam se uopće osjećao kada sam saznao da ja zapravo nisam Miroslav Baumann, nego Šalom Schwarz, i da mi onaj komadić kožice nije bio odrezan zbog fimozice u najranijem djetinjstvu, nego je to bio obred potvrde saveza s Bogom, bris, brit milah, propisno izveden na osmi dan moga života, rukom kvalificiranog mohela? Ali to zaista ovdje nitko nije znao, osim mojih švapskih roditelja Baumanna, koji su sada bili jednako pokojni kao i moji biološki, židovski roditelji Schwarzovi. (Bauer, 2011, s. 11-12)

\section{Z piętnem niemieckości żyje natomiast folksdojczka Gabriela:}

Tata je poginuo davno, odmah na početku. Javio se u domobrane jer se bojao da će ga mobilizirati u SS ili tako nešto. Ovdašnji Švabe, onoliko koliko ih je već bilo, bili su jako nepovjerljivi prema Hitleru. [...] Možda bi to ispao i mudar izbor da su okolnosti bile sretnije, da se nije našao u vlaku koji je vozio po miniranoj pruzi. (Bauer, 2011, s. 50)

Mimo że będąca Niemką Gabriela działała jako aktywistka w partii komunistycznej, organizując ochotnicze akcje pracy dla młodzieży (omladinske radne akcije), ze względu na pewne zdolności jasnowidzenia (autsajderka społeczna, „czarownica") jest bezustannie wykluczana z każdej wspólnoty: partii, Kościoła, prowincjonalnej społeczności, na końcu zostaje porzucona przez własnego syna Alberta. Tożsamość bohaterki jako ekscentrycznego odmieńca czyni ją podmiotem poza systemem, niewpisującym się w ustalone z góry ramy. „Bałkański system jest inwazyjny i nie toleruje dysydentów" (Vladanović, 2012), dlatego też tragiczny los bohaterki został przypieczętowany nieoczekiwaną śmiercią.

Konflikt dwóch zwalczających się ideologii, jakimi były komunizm i nazistowski faszyzm, nie wygasł po zakończeniu II wojny światowej. Także Gradec pozostał przestrzenią nieustającego rewanżyzmu. Linia podziału politycznego przebiega nawet przez lokalny cmentarz. Odwiedzający grób matki Frederik/ Miroslav przeżywa oburzenie na widok pomazanych przez miejscowych wandali czerwonym (sierp i młot) lub czarnym (litera U) sprejem płyt nagrobnych, sugerującym przynależność ideologiczną nieboszczyków. Frederik/Miroslav nie przynależy nigdzie, nie chce i nie zamierza mieszać się w lokalne konflikty zwaśnionych etnosów. Choć jego powrót z Ameryki w rodzinne strony został przyjęty dość entuzjastycznie przez grupę starych znajomych, mężczyzna odżegnuje się od bycia Chorwatem, jest bowiem Żydem, choć ateistą, a wcześniej sam siebie postrzegał jako naddunajskiego Niemca (adopcja Baumannów), przez wiele lat żyjąc w nieświadomości na temat swojego pochodzenia:

Njihove su riječi za mene lingvistika, razumijem ih na razini lingvistike prvenstveno, i još sam ponosan što sam toliko sačuvao, pa čak i usavršio znanje jezika koji sam kao klinac govorio samo u lokalnom dijalektu, sa sasvim osebujnim akcentima i melodijom rečenice koju danas samo prepoznajem, ali je ne mogu imitirati. (Bauer, 2011, s. 167)

${ }^{6}$ O swoim żydowskim pochodzeniu dowiedział się po latach, podobnie jak bohater powieści Igora Štiksa — Richard Richter (Štiks, 2006, 2009). 
Innym przykładem postaci o zagubionej, a raczej tłumionej, wieloaspektowej tożsamości jest wykreowana przez autora postać Alberta, syna Gabrieli, który boryka się ze stygmatem folksdojcza homoseksualisty. Jego dylematy związane z określeniem własnej identyfikacji dodatkowo komplikuje sytuacja wojny jugosłowiańskiej i rozpadu wielonarodowej federacji z połowy lat dziewięćdziesiątych XX wieku. Wysłany przez rodziców do Niemiec Albert odżegnuje się od bycia stroną w tym krwawym konflikcie, czemu daje wyraz w emocjonalnym liście do matki, przypieczętowując rozstanie się nie tylko z Chorwacją (na ojczyznę trzeba sobie zasłużyć, nie jest ona nikomu dana przez sam fakt urodzenia się w określonym miejscu), ale również z matką i najbliższą rodziną:

Nisam mogao pripadati heteroseksualnoj većini jer sam rođen takav kakav sam rođen. [...] Postoji i takozvana nacionalna pripadnost. [...] Problem a priori nije jednostavan jer se istinska pripadnost mora i zaslužiti. [...] Da bi čovjek istisnki nešto bio, da bi istniski nečemu pripadao, mora se čvrsto odreći onog mogućeg drugog, mora istinski ne-pripadati nečem drugom. Moglo bi se to i preciznije reći, ali je dovoljno razumljivo ako kažem da istinska pripadnost traži istinsku žrtvu. [...] Domovinu nemam [...]. Stalo mi je presjeći pupčanu vrpcu. [...] ja pripadam svome svijetu, Ti pripadaš svome. I ti se svjetovi uglavnom ne dodiruju. Bolje je za nas oboje, bezbolnije, da tako bude zauvijek. (Bauer, 2011, s. 187-188)

Zdaniem Magdaleny Dyras powieści chorwackiego autora „rejestrują nieustannie doświadczenie utraty" (Dyras, 2012, s. 162). Wyrzeczenia, o których wspomina Albert, a także liczne straty, jakie ponoszą w życiu inni powieściowi bohaterowie, można też postrzegać przez pryzmat transgresji, ciągłego przekraczania granic, życia na krawędzi, dokonywania wyborów, które istotnie generują zysk kosztem jakiejś utraty. Według Sławomira Kapralskiego „Tożsamość nie tyle »jest«, co »jest wytwarzana«, poprzez związane z władzą praktyki społeczne, będące niekończącym się procesem negocjacyjnym, ciągiem wymian i zapożyczeń przekraczającym granice" (Kapralski, 2010, s. 17). Przykładowo powieściowy bohater Bauera Albert traci rodzinę i ojczyznę, wyrzeka się swej niemieckiej tożsamości oraz terytorialnej przynależności do Chorwacji, lecz wybierając emigrację na zachodzie Niemiec, zyskuje swobodne życie jako homoseksualny artysta. W dodatku sam kreuje własną tożsamość, przybrawszy żydowskie nazwisko: „Promijenio sam prezime. Sada zvuči malo židovski. Time kazujem da nisam pravi Nijemac, iako sam dobio državljanstvo. Uostalom, danas je u Njemačkoj sasvim nobl biti Židov" (Bauer, 2011, s. 188).

W utworze Karusel pobrzmiewa metafora ludzkiego życia jako krótkiej, ulotnej opowieści, na którą składają się strzępy przywołanych reminiscencji, „karuzela wspomnień", bergsonowskie „utrzymywanie się obrazów przy życiu” (Bergson, 2015, s. 128). W jednym z monologów Gabriela podkreśla wybiórczy aspekt mglistej pamięci:

O rođenju svome ne znamo ništa, o djetinjstvu malo, o sazrijavanju čuvamo neke uspomene, neke bismo najradije prešutjeli i pred sobom i pred drugima, i kada se iskreno zapitamo što zaista predstavlja nekakav događaj vrijedan pamćenja, onda nam pada na pamet neka sitnica u kojoj smo se ponijeli krivo, učinili nešto nespretno, a nije trebalo, ili čak i nije bilo jako 
nespretno, ali su drugi to tako shvatili. Život se može gledati kao sasvim kratka priča, bez obzira na trajanje te fabule u stvarnom vremenu, kratka priča od nekoliko težnji, htijenja, i onda onih nekoliko nezgodnih sitnica koje pamtimo, najbolje pamtimo ono što bismo zapravo htjeli zaboraviti. (Bauer, 2011, s. 177-178)

Natomiast w utworze Toranj kiselih jabuka pamięć jawi się jako zbędny element ludzkiej egzystencji, który za sprawą niedoskonałości ludzkiego umysłu, traktującego przeszłość wybiórczo, magazynuje wspomnienia, które z czasem straciły na znaczeniu, jak pokryte kurzem księgi przechowywane na strychu:

Ali sa sjećanjima je kao s pretraživanjem knjiga koje smo zbog ovih ili onih razloga, nerijetko zbog broja, odnijeli na tavan. Kada počnemo prekapati po njima, otkrivamo zaboravljene naslove, otkrivamo prasne korice koje su nam nekada puno značile, otkrivamo ta zaboravljena značenja pa se upuštamo u listanje, u čitanje i čučimo pokraj neke od kutja što mirišu na prolaženje vremena sve dok nam noge ne utrnu. [...] Koliko nam uopće vrijede te knjige u trenutku ponovnog otkrića? Koliko znače za mene uspomene iz vrtića pokopane slojevima aktualnih sjećanja? Neke od tih uspomena kao da uopće ne razumijem. (Bauer, 2011, s. 69-70)

Powołując się na teorię Kennetha Gergena, Harald Welzer reprezentuje stanowisko, że: ,„»pamięć to dyskursywny artefakt«, samo zaś opowiadanie zawsze jest pamiętaniem. [...] »posiadanie pamięci« należy traktować jako udział w tradycji kulturowej. Mówić o czyjejś przeszłości oznacza zatem wkraczać w tradycję mowy, która posiada stosownie dobrane zasady dobrze uformowanego zadania" (Welzer, 2009, s. 41).

Również w tej powieści Bauera rola assmanowskiej pamięci zmagazynowanej przejawia się w akcie pisania/snucia opowieści, w przekazie Gabrieli do Miroslava:

Baba Roza vjerovala je da kada nekom ispričaš svoj život, predaješ svoj lik u njegove ruke, stvaraš, oblikuješ još jednoga sebe, dobivaš drugi život, još jedan, počinješ živjeti u drugome. Ja ću se predati u tvoje pa ću postojati u priči koju ti želim dati, postojat ću čak i ako me ne bude. Kao Šeherezeda. Samo... tko zna hoćeš li me onako stvarnu, poznatiju nego što sam ti sada, hoćes li me i sasvim stvarnu i dalje voljeti. (Bauer, 2011, s. 65-66)

Ulotności ludzkiej pamięci jest też świadom Albert, który uważa, że człowiek ma jedynie teraźniejszość, jego trwanie w pamięci jest uzależnione natomiast od wspomnień w umysłach innych ludzi, a ostatecznie możliwe jest przetrwanie w postaci przedmiotów, fotografii, pamiątek itp.: „Prošlost svakoga od nas u svojim opipljivim fragmentima pripada vlasniku ili vlasnicima albuma..." (Bauer, 2011, s. 188-189).

Przywołując myśl Jerzego Ziomka, trzeba wskazać, że ,dzieło literackie stanowi pewną, jednostkową opowieść o historii — i właśnie jako takie ma wartość dokumentu. Każda opowieść nawiązuje dialog z głównym nurtem historii, przetwarza go, weryfikuje i artykułuje na swój indywidualny sposób. [...] Literatura staje się więc enklawą pamięci indywidualnej, nie znaczy to jednak wcale, że nie wchodzi ona w relację z pamięcią zbiorową" (Kaniewska, 2007, s. 126). Literatura jest medium kształtującym pamięć oraz medium refleksji nad pamięcią (Erll, 
2009, s. 236). Istotnym elementem w prozatorskiej twórczości Ludwiga Bauera pozostaje przenikający się temat pamięci, tożsamości, a także braku przynależności (priča o nepripadanju) (Dimitrijević, 2012), w której za sprawą wychodzenia $\mathrm{z}$ amnezji rozbiciu ulega uporządkowany do pewnego momentu byt poszczególnych bohaterów, zmuszonych do konfrontacji z często nieprzystającymi do siebie elementami własnej tożsamości, z wielką historią w tle.

Utwory chorwackiego pisarza wpisują się w szeroki kontekst opowiadania o skomplikowanej bałkańskiej przeszłości, pełnej konfliktów i wojen, za którymi zawsze stały próby przyklejania komuś etykiet: religijnych, etnicznych, światopoglądowych, ideologicznych itp. Protagoniści prozy Bauera są nieco introwertyczni, często żyją w hermetycznym świecie własnych frustracji: „Bilo kako bilo, pamtim da sam i u ranom i u kasnijem djetinjstvu puno bio sasvim sam" (Bauer, 2013, s. 25). Autor stworzył jednak swoim postaciom możliwość lawirowania między niejednokrotnie wykluczającymi się tożsamościami. Niektórzy z nich stają zatem przed dylematem samodzielnego pokierowania swoim życiem i wyborem własnej wielowymiarowej chorwacko-niemieckiej przynależności.

\section{Bibliografia}

Anić, V., Goldstein I. (2004). Rječnik stranih riječi. Zagreb: Novi Liber.

Bal, M. (2012). Narratologia. Wprowadzenie do teorii narracji, przeł. zesp. pod red. E. Kraskowskiej i E. Rajewskiej. Kraków: Wydawnictwo Uniwersytetu Jagiellońskiego.

Bauer, L. (2011). Karusel ili Gabrijela naviješta novo doba. Zagreb: Fraktura.

Bauer, L. (2013). Toranj kiselih jabuka. Zagreb: Fraktura.

Bauman, Z. (2007). O tarapatach tożsamości w ciasnym świecie. W: W. Kalaga (red.), Dylematy wielokulturowości (s. 13-39). Kraków: Universitas.

Bergson, H. (2015). Materia i pamięć. O stosunku ciała do ducha, przeł. W. Filewicz. Kraków: vis-á-vis etiuda.

Dimitrijević, J. (2012). Veštica i svetica na ringišpilu istorije, 12.03. Pobrane z: booksa.hr (dostęp: 6.05.2019).

Dyras, M. (2012). Literackie topografie pogranicza. Przypadek Slawonii. Porównania, 11, s. 157165.

Dziamski, G. (2007). Hybrydyczna tożsamość Europy Środkowej po 1989 roku. W: W. Kalaga (red.), Dylematy wielokulturowości (s. 163-176). Kraków: Universitas.

Erll, A. (2009). Literatura jako medium pamięci zbiorowej, przeł. M. Saryusz-Wolska. W: M. Saryusz-Wolska (red.), Pamięć zbiorowa i kulturowa. Współczesna perspektywa niemiecka (s. 211-248). Kraków: Universitas.

Geiger, V. (1997). Nestanak Folksdojčera. Zagreb: Nova stvarnost.

Hirsch, M. (2011). Pokolenie postpamięci, przeł. M. Borowski, M. Sugiera. Didaskalia: gazeta teatralna, 105, s. 28-36.

Kaniewska, B. (2007). Doświadczenie historyczne w zapisie literackim. Kultura Wspótczesna, 3 (53), s. 119-128.

Kapralski, S. (2010). Pamięć, przestrzeń, tożsamość. Próba refleksji teoretycznej. W: S. Kapralski (red.), Pamięć, przestrzeń, tożsamość (s. 9-46). Warszawa: Scholar. 
Lejeune, Ph. (2010). „Drogi zeszycie..”, „drogi ekranie...”. O dziennikach osobistych, przeł. A. Karpowicz, M. i P. Rodakowie. Warszawa: Wydawnictwo Uniwersytetu Warszawskiego.

Neumann, B. (2009). Literatura, pamięć, tożsamość, przeł. A. Pełka. W: M. Saryusz-Wolskiej (red.), Pamięć zbiorowa i kulturowa. Współczesna perspektywa niemiecka (s. 249-284). Kraków: Universitas.

Niethammer, L. (2014). Po tej stronie floating gap. Pamięć zbiorowa i konstrukcja tożsamości w dyskursie naukowym, przeł. Lidex. W: K. Kończal (red.), (Kon)teksty pamięci. Antologia (s. 31-51). Warszawa: Narodowe Centrum Kultury.

Paić, Ž. (2005). Politika identiteta. Kultura kao nova ideologija. Zagreb: Antibarbaru.

Ricoeur, P. (2005). O sobie samym jako innym, przeł. M. Adaszewski. Warszawa: PWN.

Ricoeur, P. (2006). Pamięć, historia, zapomnienie, przeł. J. Margański. Kraków: Universitas.

Stjepandić, D. (2014). Književnost kao suprotnost kaosu. Pobrane z: tjedno.hr/knjizevnost-kao-suprotnost-kaosu/8.6.2014 (dostęp: 6.05.2019).

Szperlik, E. (2015). Przeszłość odkrywana zmysłami. Reminiscencje zapachów i smaków w autobiograficznej prozie obszaru postjugosłowiańskiego. Slavica Wratislaviensia, 156. Wielkie Tematy Kultury w Literaturach Stowiańskich, t. 11. Zmysty 2, s. 377-388.

Štiks, I. (2006). Elijahova stolica. Zagreb: Fraktura.

Štiks, I. (2009). Krzesło Eliasza, przeł. D. Cirlić-Straszyńska. Warszawa: W.A.B.

Vladanović, M. (2012). Ludwig Bauer: Karusel, Moderna vremena, 9.01. Pobrane z: www.mvinfo. $\mathrm{hr} /$ clanak/ludwig-bauer-karusel (dostęp: 6.05.2019).

Welzer, H. (2009). Materiał, z którego zbudowane są biografie. W: M. Saryusz-Wolska (red.), Pamięć zbiorowa i kulturowa. Współczesna perspektywa niemiecka (s. 39-58). Kraków: Universitas.

Zlatar, A. (1998). Autobiografija u Hrvatskoj: nacrt povijesti žanra i tipologija narativnih oblika. Zagreb: Matica hrvatska. 